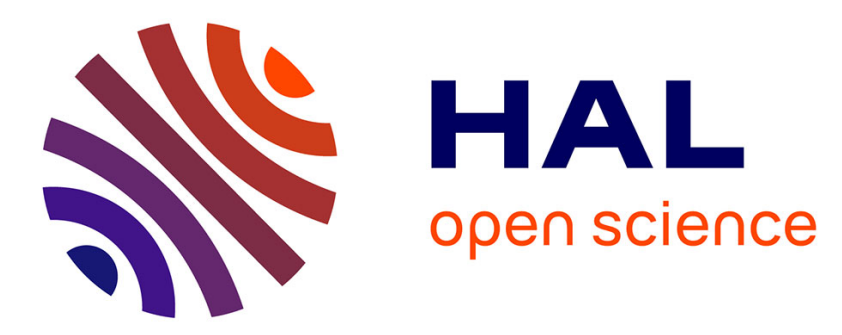

\title{
Investigating the role of irradiation defects during UO2 oxidative dissolution
}

Ritesh Mohun, L. Desgranges, A. Canizares, Nicole Raimboux, Florian Duval, R. Omnée, C. Jegou, S. Miro, Patrick Simon

\section{- To cite this version:}

Ritesh Mohun, L. Desgranges, A. Canizares, Nicole Raimboux, Florian Duval, et al.. Investigating the role of irradiation defects during UO2 oxidative dissolution. Journal of Nuclear Materials, 2018, 509, pp.305 - 312. 10.1016/j.jnucmat.2018.06.046 . insu-01868484

\section{HAL Id: insu-01868484 \\ https://hal-insu.archives-ouvertes.fr/insu-01868484}

Submitted on 6 Sep 2018

HAL is a multi-disciplinary open access archive for the deposit and dissemination of scientific research documents, whether they are published or not. The documents may come from teaching and research institutions in France or abroad, or from public or private research centers.
L'archive ouverte pluridisciplinaire HAL, est destinée au dépôt et à la diffusion de documents scientifiques de niveau recherche, publiés ou non, émanant des établissements d'enseignement et de recherche français ou étrangers, des laboratoires publics ou privés. 


\title{
Investigating the role of irradiation defects during $\mathrm{UO}_{2}$ oxidative dissolution
}

\author{
R. Mohun ${ }^{\mathrm{a}}$, L. Desgranges ${ }^{\mathrm{a}}$, A. Canizarès ${ }^{\mathrm{b}}$, N. Raimboux ${ }^{\mathrm{b}}$, F. Duval ${ }^{\mathrm{b} 1}$, R. Omnee $^{\mathrm{b}}, \mathrm{C}$.

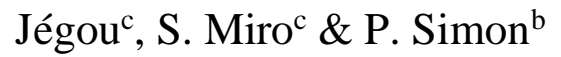 \\ a. CEA, DEN, DEC, SESC, F-13108 Saint-Paul-lez-Durance, France \\ b. CNRS, UPR 3079 CEMHTI, et Université d'Orléans, 45071 Orléans, France \\ c. CEA, DEN, DTCD, F-30207 Bagnols sur Cèze, France
}

\begin{abstract}
In this study, the behavior of alpha irradiation-induced defects in $\mathrm{UO}_{2}$, when exposed to different interfaces, is investigated. Raman spectroscopy is used to measure the formation kinetics of irradiation defects in $\mathrm{UO}_{2}$ leached under oxidizing water environment and the data are then compared to a reference $\mathrm{UO}_{2} / \mathrm{Ar}$ system. The results reveal that the presence of either aerated water or inert argon gas modifies the formation kinetics of irradiation defects. The $\mathrm{UO}_{2}$ alteration in aerated water leads to the precipitation of secondary phases in the form of studtite and water chemical analysis reveals that the $\mathrm{UO}_{2}$ dissolution mechanism proceeds without the formation of an oxidized $\mathrm{UO}_{2}$ layer.
\end{abstract}

Keywords: Irradiation defects, Raman spectroscopy, aerated water, secondary phases

\section{Introduction}

The safe management of spent nuclear fuels remains one of the main concerns facing the modern nuclear industry and a major international effort is currently underway in order to propose suitable management and disposal procedures. One major scientific question associated with this industrial issue deals with the behavior of spent nuclear fuels in the presence of water. It is of utmost importance to acquire sufficient data for understanding the irradiated fuel leaching behavior.

The anoxic dissolution of nuclear fuels has been extensively studied and suitable mechanisms have been proposed by Shoesmith et al. [1]. Relevant data on the oxidative dissolution of $\mathrm{UO}_{2}$ and $\mathrm{MOX}$ fuels under the influence of irradiation are also available [2, 3, 4, 5, 6]. It is worth noting that previous studies were principally devoted to characterizing the oxidation of the fuel matrix [7], the uranium and plutonium release rates $[8,9]$, and the effect of $\mathrm{H}_{2} \mathrm{O}_{2}$ and radiolytic radicals on the dissolution mechanisms $[10,11,12,13]$. The effect of burn-up has also been reported through the measurements of fission product release $[14,15,16]$. However, little is known about the irradiation defects within the spent nuclear fuels during their interaction with the aqueous medium.

Post-irradiation, about $95 \%$ of the spent fuel still consists of $\mathrm{UO}_{2}$ while the remaining $5 \%$ is distributed amongst fission products and transuranic elements. The dissolution of the $\mathrm{UO}_{2}$ matrix

\footnotetext{
${ }^{1}$ now at ISTO, CNRS/Université Orleans, F-45100 Orleans.
} 
thus governs the release of radionuclides from the irradiated fuels. It has been speculated that irradiation-induced damages involving the accumulation of point defects in the crystalline structure affect the chemical durability of nuclear fuels [17, 18]. However, the latter is difficult to quantify in $\mathrm{UO}_{2}$ because several factors impact its normal dissolution such as the oxidation of $\mathrm{U}(\mathrm{IV})$ into more soluble U(VI), amongst others [19].

Several studies have been performed using $\mathrm{CeO}_{2}$ compounds that aimed to investigate the specific role of defect structures. Oxygen vacancy defects can be induced in $\mathrm{CeO}_{2}$ by doping, hightemperature annealing in an oxygen-deficient atmosphere or even ionic irradiation. Findings from previous studies have shown that the cationic release rate of $\mathrm{CeO}_{2-\mathrm{x}}$ is more significant compared to stoichiometric $\mathrm{CeO}_{2}$ compounds. For instance, Horlait et al. [20] evidenced a considerable decrease in the chemical durability of $\mathrm{CeO}_{2}$ doped with $\mathrm{Ln}$ ions. Similar leaching trends were also observed for $\mathrm{CeO}_{2-\mathrm{x}}$ obtained through both precise synthesis methods [19] and Xe ionic implantation [21]. On the other hand, the amorphization of ceramic wastes also leads to a significant effect on the leaching mechanisms as previously reported by Ollila et al. [22] and Matzke [23]. Though $\mathrm{UO}_{2}$ does not undergo such behavior during ionic implantation, the presence of irradiation-induced lattice defects might influence the dissolution rate.

This study aims to elucidate the effect of alpha irradiation on the $\mathrm{UO}_{2}$ oxidative dissolution mechanisms and also provides a rigorous analysis of the irradiation defects during a potential $\mathrm{UO}_{2}$ matrix-water interaction by means of Raman spectroscopy. The latter is a powerful characterization tool for the identification of the altered secondary phases formed during dissolution experiments [24]. Raman spectroscopy has also proven its reliability for the investigation of atomic defects in nuclear fuels. The occurrence of a specific Raman signature, referred to as the Raman triplet defect bands, in both doped and irradiated $\mathrm{UO}_{2}$, appears as a promising path for the understanding of atomic defects in nuclear fuels [25, 26, 27, 28]. In this paper, we present the application of a newly developed in situ experimental setup to monitor the formation kinetics of the Raman defect bands during the alpha irradiation of $\mathrm{UO}_{2}$ when exposed to different interfaces.

\section{Experimental}

\subsection{Materials}

Sintered $\mathrm{UO}_{2}$ ceramics ( $8 \mathrm{~mm}$ diameter and $300 \mu \mathrm{m}$ thickness) were manufactured at the Laboratoire des Combustibles Uranium (LCU) at CEA-Cadarache, France. The pellets were heattreated at $1400^{\circ} \mathrm{C}$ under dry $\mathrm{Ar} / \mathrm{H}_{2}$ and mirror polished on one surface for subsequent in situ and ex situ characterizations.

\subsection{Irradiation conditions}

The alpha irradiation was performed using a cyclotron device at the "Conditions Extrêmes et Matériaux: Haute Température \& Irradiation” (CEMHTI) Laboratory at Orléans, France. The 
irradiation was carried out under two different settings: $(a) \mathrm{UO}_{2}$ in contact with a reactive interface (aerated water) and $(b) \mathrm{UO}_{2}$ in the presence of an inert gaseous medium (argon gas).

For both experiments, the $\mathrm{UO}_{2}$ pellets were irradiated with a $45 \mathrm{MeV}$ alpha beam during 2 hours to deliver a final fluence of $7.07 \times 10^{15} \alpha / \mathrm{cm}^{2}$. Under such conditions, the alpha particles are allowed to pass through the pellets and are then attenuated in the contact medium. An estimated defect concentration of $3.62 \times 10^{-2}$ in the $\mathrm{UO}_{2}$ bulk per ion was determined by the SRIM simulation software [29].

\subsubsection{Irradiation of $\mathrm{UO}_{2}$ in contact with aerated water}

A full description of the experimental installation used in this study was previously detailed by our colleagues [30]. The setup consists of an irradiation chamber and a safety area. For the leaching experiment, a newly developed sample holder was placed in the irradiation chamber which maintained the mirror polished $\mathrm{UO}_{2}$ surface in contact with aerated water and the non-polished surface was exposed to the alpha beam. Before irradiation, the pellet was washed with carbonated water $\left(10^{-3} \mathrm{M}\right)$ during two cycles of sequential pre-leaching $(2 \times 1 \mathrm{hr}$.) to remove any traces of oxidized layer from the $\mathrm{UO}_{2}$ surface. Two other sequential pre-leaching with pure aerated demineralized water were also performed $(2 \mathrm{x} 1 \mathrm{hr}$.) to quantify the concentration of dissolved uranium before irradiation. The sample holder was then filled with $15 \mathrm{~mL}$ aerated deionized water and the $\mathrm{pH}$ was kept in equilibrium with air, close to $\sim 5.5$.

The alpha irradiation induces atomistic damages in the $\mathrm{UO}_{2}$ bulk. The incident ions then emerge from the $\mathrm{UO}_{2}$ disk at $5 \mathrm{MeV}$ and are attenuated over a distance of $37 \mu \mathrm{m}$ in the water solution [29]. The attenuation of the alpha particles initiates a water radiolysis process which leads to the production of several radiolytic species such as radicals, hydrated electrons and hydrogen peroxide $\left(\mathrm{H}_{2} \mathrm{O}_{2}\right)$. During alpha water radiolysis, the formation of molecular species is favored mainly due to the recombination of short-lived radicals in the tracks since the density of ionization events is greater with alpha particles compared to low-LET particles [31, 32]. Though short-lived radicals can also contribute to the dissolution experiment, this study was solely focused on the effect of highly oxidizing $\mathrm{H}_{2} \mathrm{O}_{2}$. Long-lived $\mathrm{H}_{2} \mathrm{O}_{2}$ is more stable and diffuses homogeneously in the solution. Thus, their effect on the dissolution can be easily quantified and is discussed in this paper. A motorized Raman probe positioned on a three-dimensional XYZ motion-control system (Newport MFA 25 and ILS 250 stages) was installed in the irradiation chamber for the in situ monitoring of the $\mathrm{UO}_{2} / \mathrm{H}_{2} \mathrm{O}$ interface during irradiation.

The essential components of the in situ Raman spectroscopy were kept in the safety area, located $20 \mathrm{~m}$ away from the irradiation chamber, to prevent equipment damage due to irradiation. The safety area and the irradiation chamber were relayed by means of optical fibers and electric cables. 


\subsubsection{Irradiation of $\mathrm{UO}_{2}$ under inert gaseous (Ar) medium}

The $\mathrm{UO}_{2}$ ceramic was placed in the same configuration as detailed in Section 2.2.1, except that the aerated water solution was replaced by a chemically inert gaseous medium. Argon gas was used for this study because it provides an inert $\mathrm{UO}_{2}$ boundary to which the mechanisms occurring near the $\mathrm{UO}_{2}-\mathrm{H}_{2} \mathrm{O}$ interface can be compared. The attenuation of alpha particles in the gaseous medium

generates an argon plasma which appears as an intense and narrow peak at $825 \mathrm{~cm}^{-1}$ on the Raman spectrum with the red $(632.8 \mathrm{~nm})$ excitation laser.

This experiment is similar to the study previously performed by Guimbretière et al. [33] except that the measurements were largely optimized to allow the acquisition of Raman spectra of the highest quality.

\subsection{In situ Raman measurements}

The irradiation-induced changes occurring near the $\mathrm{UO}_{2}$ interface were monitored by a Renishaw RA-100 Raman Analyzer. The laser spot of the portable Renishaw RA-100 device is $\sim 8 \mu \mathrm{m}$. Guimbrètiere et al. [26] showed the existence of a $\mathrm{UO}_{2}$ grain boundary Raman signal at $555 \mathrm{~cm}^{-1}$. For the need of this study, a $\mathrm{UO}_{2}$ disk was carefully chosen which did not show significant contribution of the grain boundary signal because the latter appears in the same spectral range as the irradiation-induced Raman signals.

A $632.8 \mathrm{~nm} \mathrm{He}-\mathrm{Ne}$ red laser and a holographic grating of 1800 grooves/mm were sufficient to allow 2-3 $\mathrm{cm}^{-1}$ spectral resolution. The spectroscopy uses a Mitutoyo microscope objective (x20) which enables a focal length of $30.5 \mathrm{~mm}$, giving a depth field of about $300 \mu \mathrm{m}$. However, the high absorbing properties of $\mathrm{UO}_{2}$ restrict the probing depth only to the pellet surface. The Raman spectra were obtained with an acquisition time of $120 \mathrm{~s}$ after 5 accumulations in the $300-1000 \mathrm{~cm}^{-1}$ spectral range using a multichannel CCD (576 x 401 pixels) detector.

\subsection{Ex situ Raman characterizations}

The ex situ measurements of the irradiated $\mathrm{UO}_{2}$ disks were carried out by a Renishaw Invia Reflex high-confocal spectrometer. The latter was also equipped with a $632.8 \mathrm{~nm}$ excitation laser and a holographic grating of 1800 grooves/mm for a spectral acquisition between 300 and $900 \mathrm{~cm}^{-1}$. The $\mathrm{UO}_{2}$ grains and grain boundary attacks were analyzed by performing Raman spectral mappings over a selected area of the leached surface after the dissolution experiment. The dimensions of the chosen area were $55 \times 25 \mu \mathrm{m}^{2}$ on the $\mathrm{x}$ and $\mathrm{y}$-axis respectively, with a moving step of $1 \mu \mathrm{m}$ in the snake mapping mode.

\subsection{Scanning Electron Microscopy (SEM) and X-ray diffraction (XRD) measurements}

The SEM and XRD measurements were carried out at the LCU lab at CEA-Cadarache. For the SEM analysis, a Philips XL30 FEG device was used and part of the $\mathrm{UO}_{2}$ leached surface was 
covered with a thin silver lac film to increase electron conduction for the acquisition of highresolution images.

In regard to XRD measurements, a D8 Bruker diffractometer (45 kV, $40 \mathrm{~mA})$ mounted in a BraggBrentano configuration with copper radiation from a conventional tube source $\left(\lambda K \alpha_{1}=1.5406 \AA\right.$, $\lambda K \alpha_{2}=1.5444 \AA$ ) was used. The diffractometer is equipped with a graphite monochromator and a $\mathrm{NaI}$ scintillation 269 detector. The diffraction patterns were recorded for a scan in the $20^{\circ}-140^{\circ}$

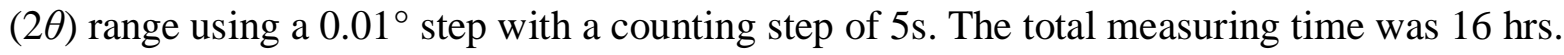

\subsection{Irradiated water solution analysis}

The water solution was removed from the sample holder and transferred into suitable flasks after the irradiation experiment. The solution analysis was performed at the Laboratoire des Matériaux et Procédés Actifs (LMPA) at CEA-Marcoule to determine the concentration of radiolytic $\mathrm{H}_{2} \mathrm{O}_{2}$ and dissolved uranium.

Molecular $\mathrm{H}_{2} \mathrm{O}_{2}$ rapidly dissociates into hydroxyl radicals under continuous UV light exposure. The flasks were thus wrapped in aluminum foil and stored at low temperature $\left(\sim 4^{\circ} \mathrm{C}\right)$ to measure the quantitative amount of radiolytic $\mathrm{H}_{2} \mathrm{O}_{2}$ produced by the alpha particles. The spectrophotometric Ghormley method [34] was used to determine the concentration of $\mathrm{H}_{2} \mathrm{O}_{2}$ in the solution ranging from $4 \times 10^{-6} \mathrm{M}$ to $2 \times 10^{-4} \mathrm{M}$. The dissolved uranium in the solution was measured by a laserinduced Kinetic Phosphorescence Analyzer (KPA) with a quantitative limit of $0.1 \mu \mathrm{g} / \mathrm{L}$.

\section{Results}

\subsection{In situ Raman measurements}

Figure 1 shows the in situ Raman spectra acquired during the alpha irradiation of the $\mathrm{UO}_{2} / \mathrm{H}_{2} \mathrm{O}$ interface. 


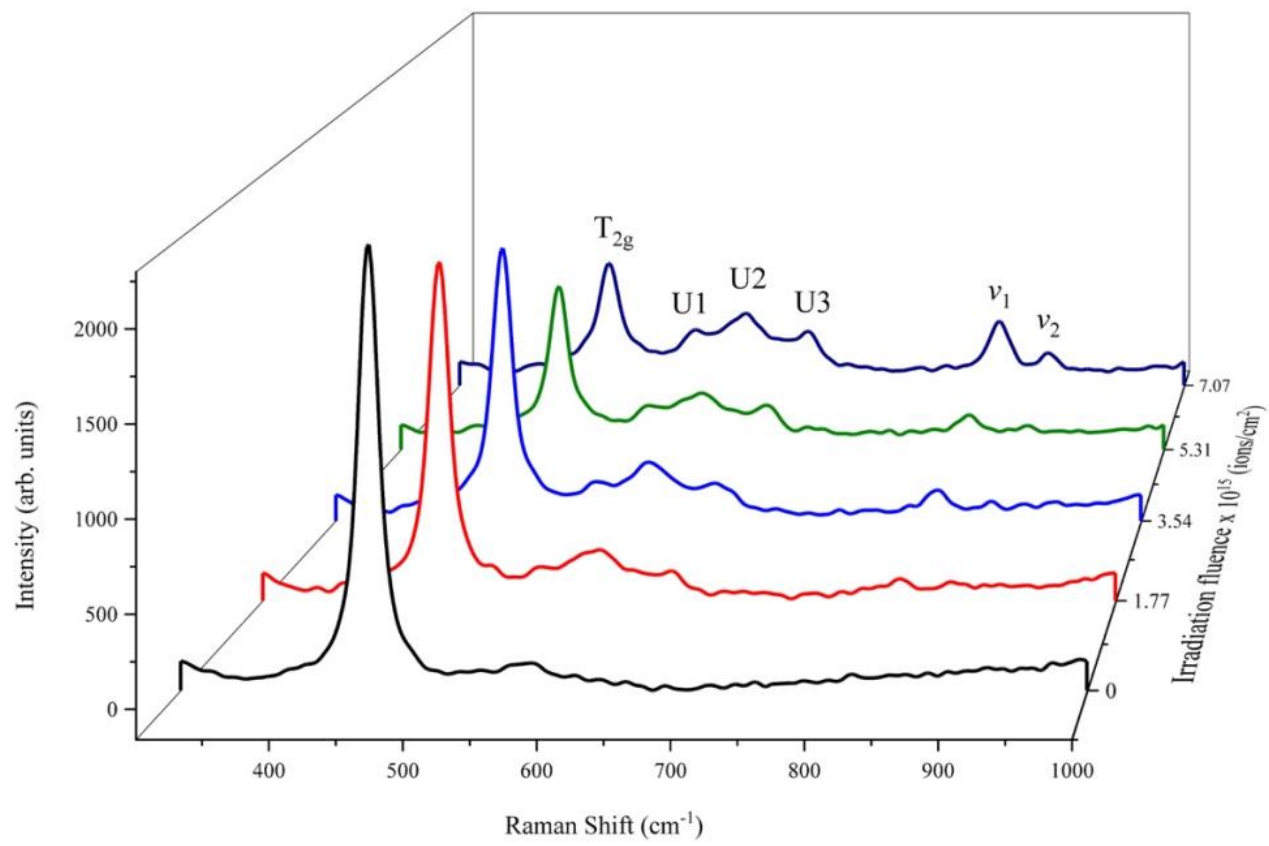

Figure 1: In situ Raman acquisitions of the $\mathrm{UO}_{2} / \mathrm{H}_{2} \mathrm{O}$ system as a function of increasing alpha irradiation fluence

Before irradiation, the Raman spectrum of the $\mathrm{UO}_{2}$ sample indicates the presence of the triply degenerate Raman active $T_{2 \mathrm{~g}}$ mode occurring at $445 \mathrm{~cm}^{-1}$. This peak is referred to as the symmetry Raman-allowed phonon scattering of $\mathrm{UO}_{2}$ and is the signature of compounds sharing the $\mathrm{Fm} 3 \mathrm{~m}$ space group. The absence of other noticeable peaks suggests that the $\mathrm{UO}_{2}$ disk was close to stoichiometry before the irradiation experiment.

The alpha irradiation affects the $\mathrm{T}_{2 \mathrm{~g}}$ peak (decrease in the intensity accompanied by a peak broadening). Similar observations were previously reported by Guimbretière et al. [35]. The irradiation also induces the apparition of three additional peaks in the $500-660 \mathrm{~cm}^{-1}$ spectral range. These peaks are referred to as the Raman triplet defect bands (U1: $\sim 527 \mathrm{~cm}^{-1}, \mathrm{U} 2: \sim 575 \mathrm{~cm}^{-1}$ \& U3: $\sim 635 \mathrm{~cm}^{-1}$ ) and correspond to the presence of irradiation damages [36, 37, 38, 39]. Figure 1 shows that the intensity of the defect bands grows continuously with the increase of the alpha irradiation fluence and is consistent with the increase defect concentration in the $\mathrm{UO}_{2}$ bulk.

Radiolytic $\mathrm{H}_{2} \mathrm{O}_{2}$ can enhance both the $\mathrm{UO}_{2}$ oxidation and the uranium dissolution rate in the form of uranyl ions $\left(\mathrm{UO}_{2}{ }^{2+}\right)$. These ions precipitate as secondary phases on the pellet surface once the water solution reaches the solubility limit for the formation of $\mathrm{U}(\mathrm{VI})$ phases. The two distinct peaks occurring at $820 \mathrm{~cm}^{-1}$ and $865 \mathrm{~cm}^{-1}$ on the spectra are signatures of the studtite secondary phase ( $\left.\mathrm{UO}_{2} \cdot\left(\mathrm{O}_{2}\right) \cdot 4 \mathrm{H}_{2} \mathrm{O}\right)$. According to Amme et al. [24], the $820 \mathrm{~cm}^{-1}$ peak corresponds to the symmetrical axial stretching mode of uranyl ion $\left(\mathrm{UO}_{2}{ }^{2+}\right)\left(v_{1}\right)$ and the $865 \mathrm{~cm}^{-1}$ band is attributed to peroxide ion $\left(\mathrm{O}_{2}{ }^{2-}\right)\left(v_{2}\right)$ in the studtite structure. 


\subsection{SEM analysis}

Prior to irradiation, the SEM image of the polished surface clearly indicates the $\mathrm{UO}_{2}$ grains and grain boundaries (Figure 2a). At the end of the leaching experiment, the irradiated $\mathrm{UO}_{2}$ disk was dismantled from the sample holder and dried to analyze the surface microscopic evolution.

The radiolytic attack brings significant changes to the microstructure. Figure $2 b$ shows the formation of a homogeneously distributed thick altered layer displaying micro-cracks over the entire surface. The sample was tilted to $35^{\circ}$ to the direction of the electron beam and the thickness of the altered layer was estimated to be in the 1-2.5 $\mu \mathrm{m}$ range (Figure $2 \mathrm{c} \&$ Figure $2 \mathrm{~d}$ ).
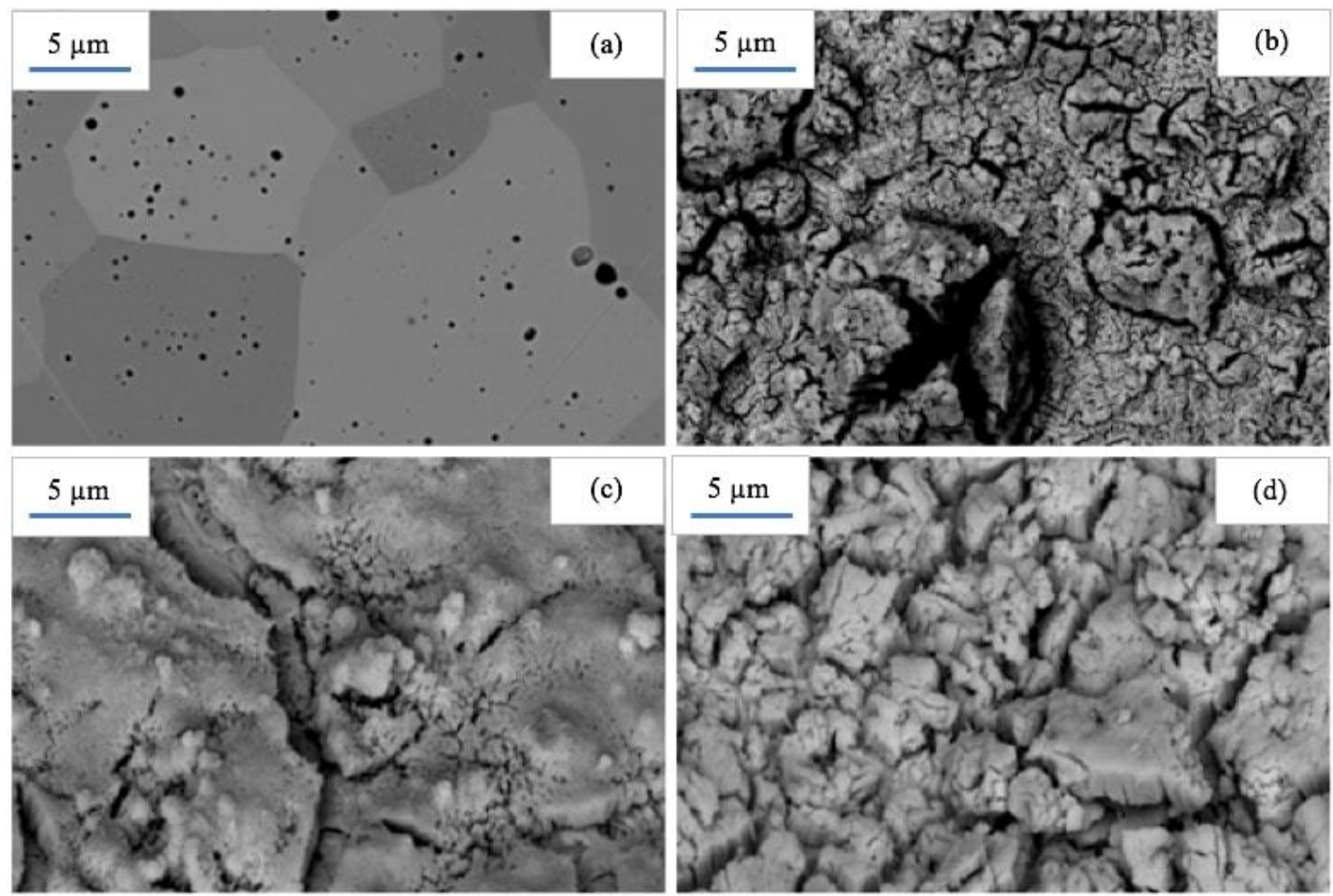

Figure 2: SEM images of the $\mathrm{UO}_{2}$ surface $(a)$ before and $(b-d)$ after leaching under alpha irradiation; $(b)$ : tilt $0^{\circ} \&(c-d)$ : tilt $35^{\circ}$

\subsection{Ex situ Raman mapping}

The SEM images show that the studtite phase remains thin enough to be transparent in the visible spectral range. The ex situ Raman mapping was performed to extract relevant information regarding the $\mathrm{UO}_{2}$ grains, grain boundaries and studtite phase.

Figure 3 shows the microscope image of the mapped leached surface area. The bright green color indicates the highly oxidized regions and the blue color corresponds to the low altered zones. The high intensity of the studtite phase shows that the grain boundary regions were preferentially 
attacked compared to the $\mathrm{UO}_{2}$ grains. These observations are in good agreement with Traboulsi et al. [40].

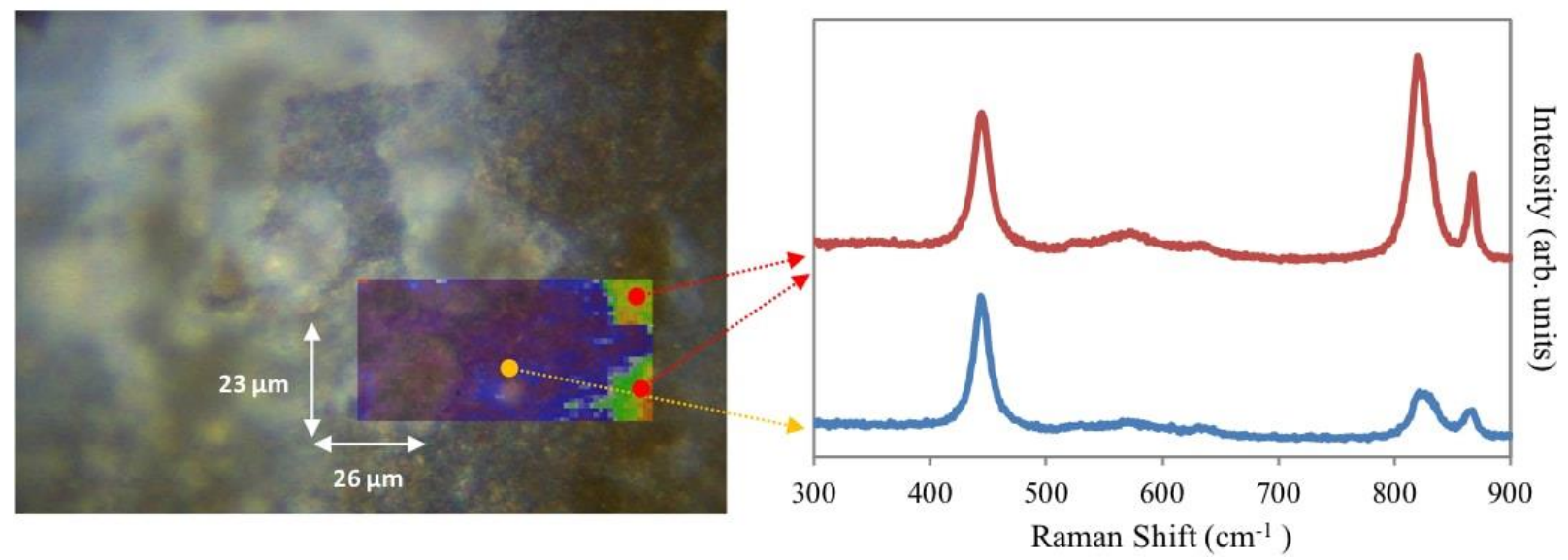

Figure 3: Space-resolved Raman spectral mapping of the irradiated $\mathrm{UO}_{2}$ surface showing the grains (Blue color) and grain boundary regions (Green color). (For interpretations of the references to color in this figure, the reader is referred to the online version of this manuscript).

\subsection{XRD measurements}

XRD method was used to confirm the exact nature of the secondary altered phases. The obtained data (not presented in this paper) showed the presence of metastudtite $\left(\mathrm{UO}_{2}\left(\mathrm{O}_{2}\right) \cdot 2 \mathrm{H}_{2} \mathrm{O}\right)$ on the fuel surface. The presence of metastudtite evidenced at this stage of analysis was due to the combined effects of air exposure and studtite dehydration after the SEM and ex situ Raman analysis [41]. The XRD measurements thus suggest that studtite was initially precipitated during the leaching experiment and are therefore consistent with the in situ and ex situ Raman data. It is worth noting that the schoepite phase $\left(\mathrm{UO}_{3} .2 \mathrm{H}_{2} \mathrm{O}\right)$ was not unambiguously observed in our study [24].

\subsection{Solution analysis}

The dissolved uranium concentration before irradiation was measured from the water solution used for the two sequential pre-leaching steps. The uranium release was observed to decrease from 1.93 $\pm 0.20 \mu \mathrm{g} / \mathrm{L}$ to $0.121 \pm 0.012 \mu \mathrm{g} / \mathrm{L}$.

The concentration of radiolytic $\mathrm{H}_{2} \mathrm{O}_{2}$ and dissolved uranium contained in the solution after irradiation were quantified and are presented in Table 1. The analysis also revealed a high concentration of fluoride and chloride ions in the water solution. These ions originate from the polychlorotrifluoroethylene (PCTFE) polymer used for the fabrication of the sample holder. The polymer material was chosen because it provides excellent resistance to radiolytic attack. The 
complexing and corrosive characteristics of fluoride ions are likely to affect the $\mathrm{UO}_{2}$ dissolution mechanisms.

Table 1: Detailed analysis of the irradiated solution showing the concentration of radiolytic $\mathrm{H}_{2} \mathrm{O}_{2}$ and dissolved uranium. The concentration of fluoride and chloride ions released from the sample holder is also reported

\begin{tabular}{c|c|c|c|c}
\hline & $\begin{array}{c}\text { Molecular } \mathbf{H}_{2} \mathbf{O}_{2} \\
(\mathbf{m o l} / \mathbf{L})\end{array}$ & $\begin{array}{c}\text { Dissolved } \\
\text { uranium }(\boldsymbol{\mu g} / \mathbf{L})\end{array}$ & $\begin{array}{c}\text { Fluoride ions } \\
(\mu \mathrm{g} / \mathrm{L})\end{array}$ & $\begin{array}{c}\text { Chloride ions } \\
(\boldsymbol{\mu g} / \mathbf{L})\end{array}$ \\
\hline Measured value & $5.4 \times 10^{-3}$ & 207 & 890 & 570 \\
\hline Uncertainty & $\pm 1.1 \times 10^{-3}$ & \pm 21 & \pm 180 & \pm 110 \\
\hline
\end{tabular}

\section{Discussion}

The $\mathrm{UO}_{2}$ oxidative dissolution mechanisms will first be discussed based on the findings obtained during the detailed chemical analysis of the irradiated water solution. The formation kinetics of alpha irradiation-induced defects in the $\mathrm{UO}_{2}$ bulk will then be analyzed to determine their behavior during the dissolution process.

\section{1. $\mathrm{UO}_{2}$ oxidative dissolution}

The measured $\mathrm{H}_{2} \mathrm{O}_{2}$ concentration is found to be of the same order as those previously reported by Corbel et al. [2] and Sattonnay et al. [4]. Shoesmith et al. [42] investigated the effect of $\mathrm{H}_{2} \mathrm{O}_{2}$ on the $\mathrm{UO}_{2}$ dissolution rate. The authors showed that the concentration of dissolved uranium increases with a first-order dependence when the $\mathrm{H}_{2} \mathrm{O}_{2}$ concentration is close to $5.4 \times 10^{-3} \mathrm{~mol} / \mathrm{L}$. The saturation index (SI) of the irradiated water solution for the studtite precipitation was then determined using the equilibrium reaction between $\mathrm{UO}_{2}{ }^{2+}$ ions and $\mathrm{H}_{2} \mathrm{O}_{2}$ (Equation 1).

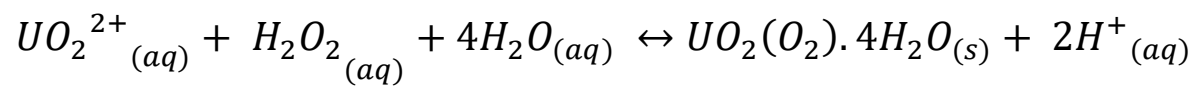

The SI for the precipitation of studtite phase is obtained from Equation 2.

$$
S I_{(\text {studtite })}=\log \frac{\frac{\left[\mathrm{UO}_{2}{ }^{2+}\right] \cdot\left[\mathrm{H}_{2} \mathrm{O}_{2}\right]}{\left[\mathrm{H}^{+}\right]^{2}}}{K S_{\text {studtite }}}
$$

Where $\log$ Ksstudtite $=-2.86$ and represents the solubility constant for studtite [43].

The conditions for studtite precipitation are as follows: 
SI $<0$ : under-saturation (no precipitation of secondary phases)

SI $\geq 0$ : solubility limit for the formation of studtite (precipitation of secondary phases is favored)

The calculated saturation index value ( $\mathrm{SI}=3.53$ ) indicates that the irradiated water solution was over-saturated and the formation of the studtite phase was favored. This result is in good agreement with the Raman, SEM, and XRD findings. According to Equation 1, the precipitation of secondary phases increases the solution acidity. In this study, it was evidenced that the $\mathrm{pH}$ of the water solution decreased from $\sim 5.5$ (before irradiation) to 4.5 (after irradiation). According to Torrero $e t$ al. [44], the $\mathrm{UO}_{2}$ oxidative dissolution mechanisms proceed with little surface oxidation under such slightly acidic conditions.

The high concentration of corrosive fluoride ions should also be considered in the dissolution mechanisms mainly due to their excellent complexing ability toward uranium ions. They form strong $\mathrm{UO}_{2} \mathrm{~F}^{+}$(aq) ligands with free uranyl ions in the solution but also tend to complex the $\mathrm{UO}_{2}$ surface. Thus, the combined effects of solution $\mathrm{pH}$ and complexing ions suggest that the dissolution mechanisms occur without the formation of an oxidized $\mathrm{UO}_{2}$ layer. Raman measurements confirmed the absence of fuel oxidation because no peaks relevant to hyper-stoichiometric $\mathrm{UO}_{2}$ were observed. Indeed, compared to irradiated $\mathrm{UO}_{2}$ where the Raman defect bands (U1: $\sim 27 \mathrm{~cm}^{-}$ 1, U2: $\sim 575 \mathrm{~cm}^{-1} \& \mathrm{U} 3: \sim 635 \mathrm{~cm}^{-1}$ ) appear in the 500-660 $\mathrm{cm}^{-1}$ spectral range, hyper-stoichiometric $\mathrm{UO}_{2}$ is characterized by a small hump at $530 \mathrm{~cm}^{-1}$ and an intense asymmetric band at $630 \mathrm{~cm}^{-1}$ [ 45 , $46,47,48,49]$.

\subsection{In situ Raman analysis: Irradiation defects}

Figure 4 shows three in situ Raman spectra (only the $450-700 \mathrm{~cm}^{-1}$ range) of the $\mathrm{UO}_{2} / \mathrm{H}_{2} \mathrm{O}$ system irradiated at different alpha fluence. The figure depicts the growing intensity of the defect bands (U1, U2 \& U3) under increasing irradiation fluence. 


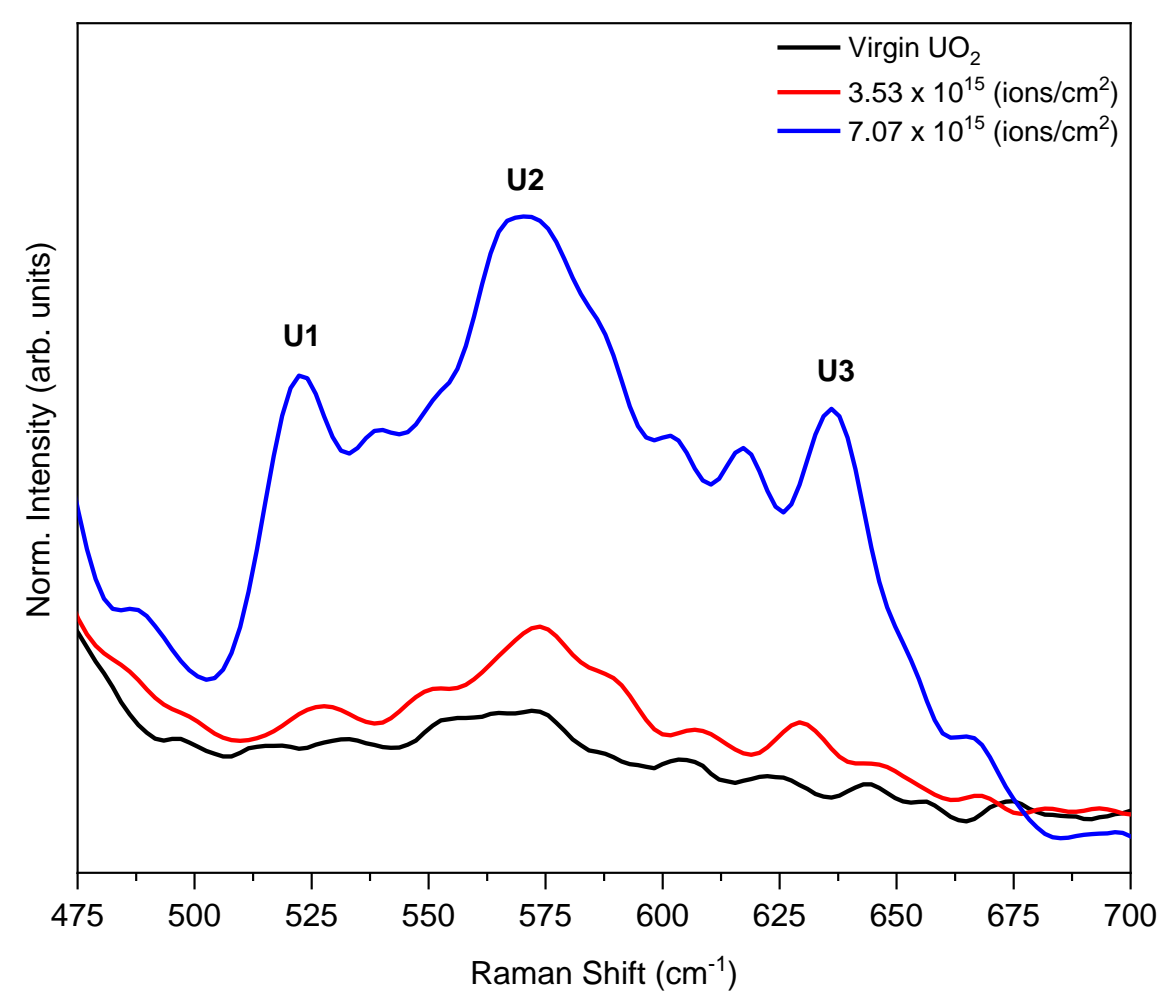

Figure 4: In situ evolution of the Raman triplet defect peaks during irradiation of the $\mathrm{UO}_{2} / \mathrm{H}_{2} \mathrm{O}$ system

The in situ spectra were collected with an excellent signal-to-noise ratio and offered the advantage of a precise analytical data treatment to study the kinetics of the U1, U2 \& U3 bands. The defect kinetics, presented in Figure 5, were obtained after the removal of background noises (baseline subtraction) followed by averaging the intensity of the triplet defect bands occurring between 500 and $660 \mathrm{~cm}^{-1}$. 


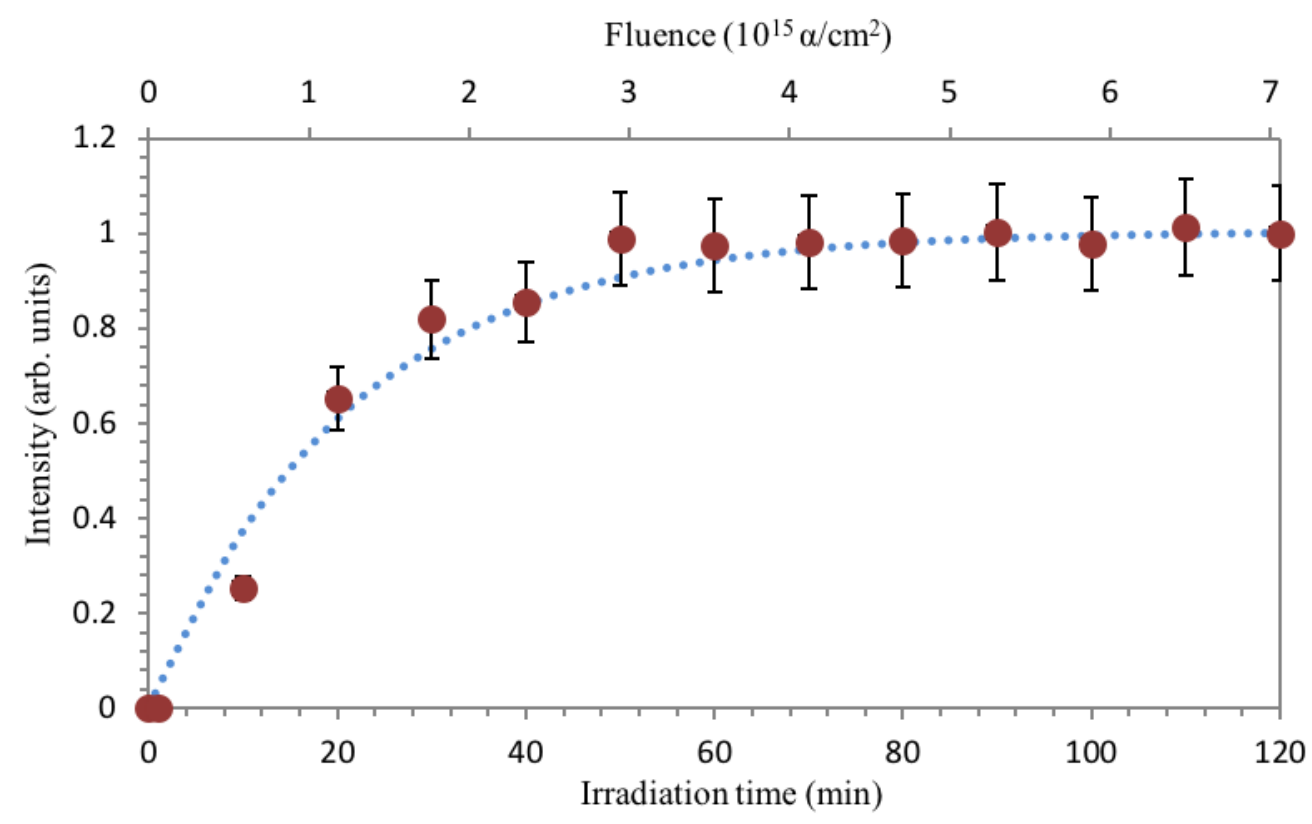

Figure 5: Kinetics of Raman triplet defect bands intensity (Red dots) fitted with the Direct Impact model (Blue dotted line) for the $\mathrm{UO}_{2} / \mathrm{H}_{2} \mathrm{O}$ system under alpha irradiation. (For interpretations of the references to color in this figure, the reader is referred to the online version of this manuscript).

The data presented in Figure 5 were then compared to the reference $\mathrm{UO}_{2} / \mathrm{Ar}$ system to provide a better interpretation of the observed kinetics. Figure 6 illustrates the in situ Raman spectra acquired during the alpha irradiation of the $\mathrm{UO}_{2}$ disk exposed to the chemically inert argon environment.

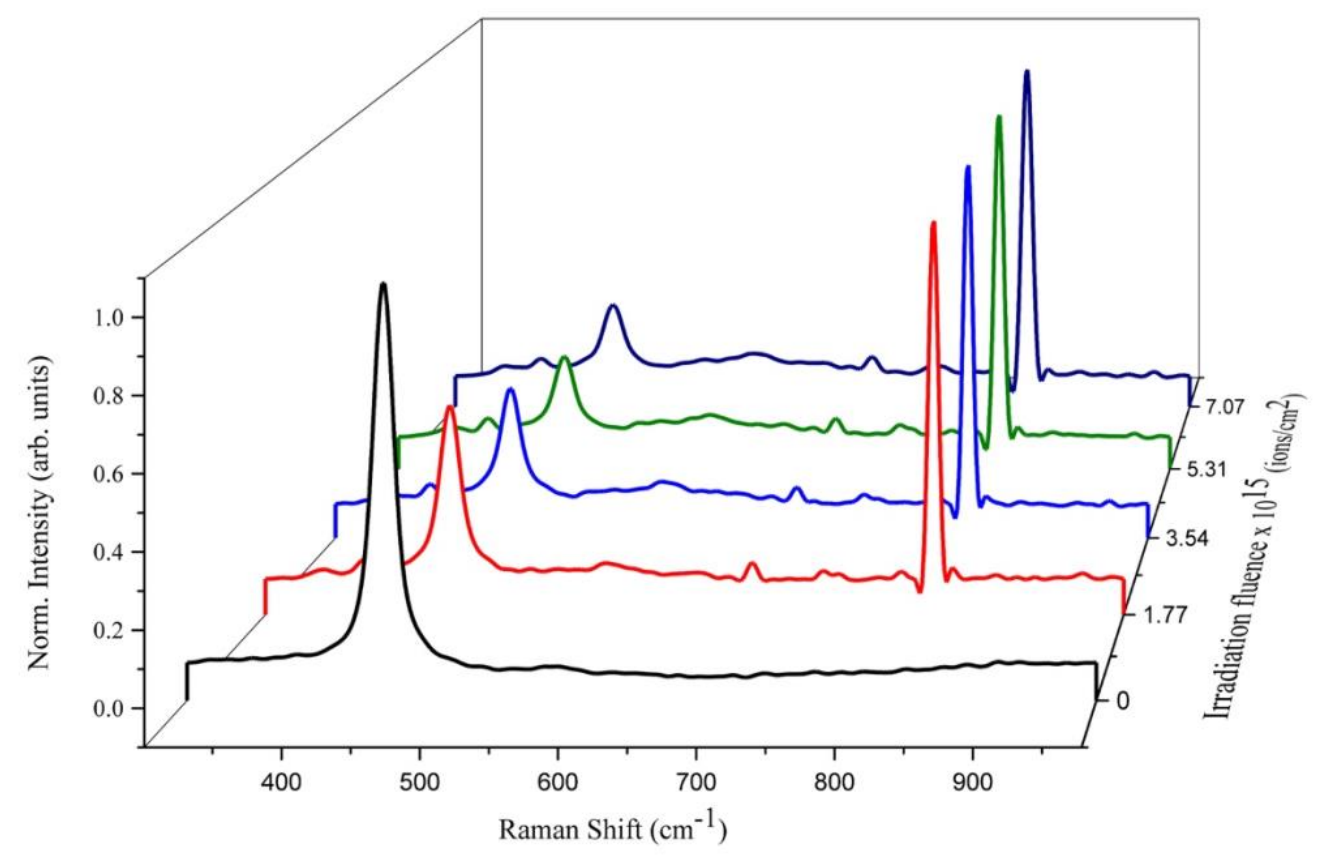

Figure 6: In situ evolution of the Raman spectra acquired during the alpha irradiation of the $\mathrm{UO}_{2} / \mathrm{Ar}$ system 
Figure 6 shows an important decrease of the $\mathrm{T}_{2 \mathrm{~g}}$ intensity during the initial stages of irradiation. The $\mathrm{T}_{2 \mathrm{~g}}$ band broadening as a function of irradiation fluence can also be evidenced. The argon plasma resulting from the attenuation of alpha particles in the gaseous contact medium appears as the intense peak at $825 \mathrm{~cm}^{-1}$ (relative to $633 \mathrm{~nm}$ reference, i.e., $667.9 \mathrm{~nm}$ as wavelength). Another plasma line of lower intensity can be observed just below $700 \mathrm{~cm}^{-1}$. The high intensity of the plasma rays slightly masks the Raman triplet defect bands and needs to be corrected to extract the defect kinetics.

Figure 7 highlights the $475-700 \mathrm{~cm}^{-1}$ spectral range and the behavior of the U1, U2 and U3 peaks during the irradiation of the $\mathrm{UO}_{2} / \mathrm{Ar}$ system can be observed.

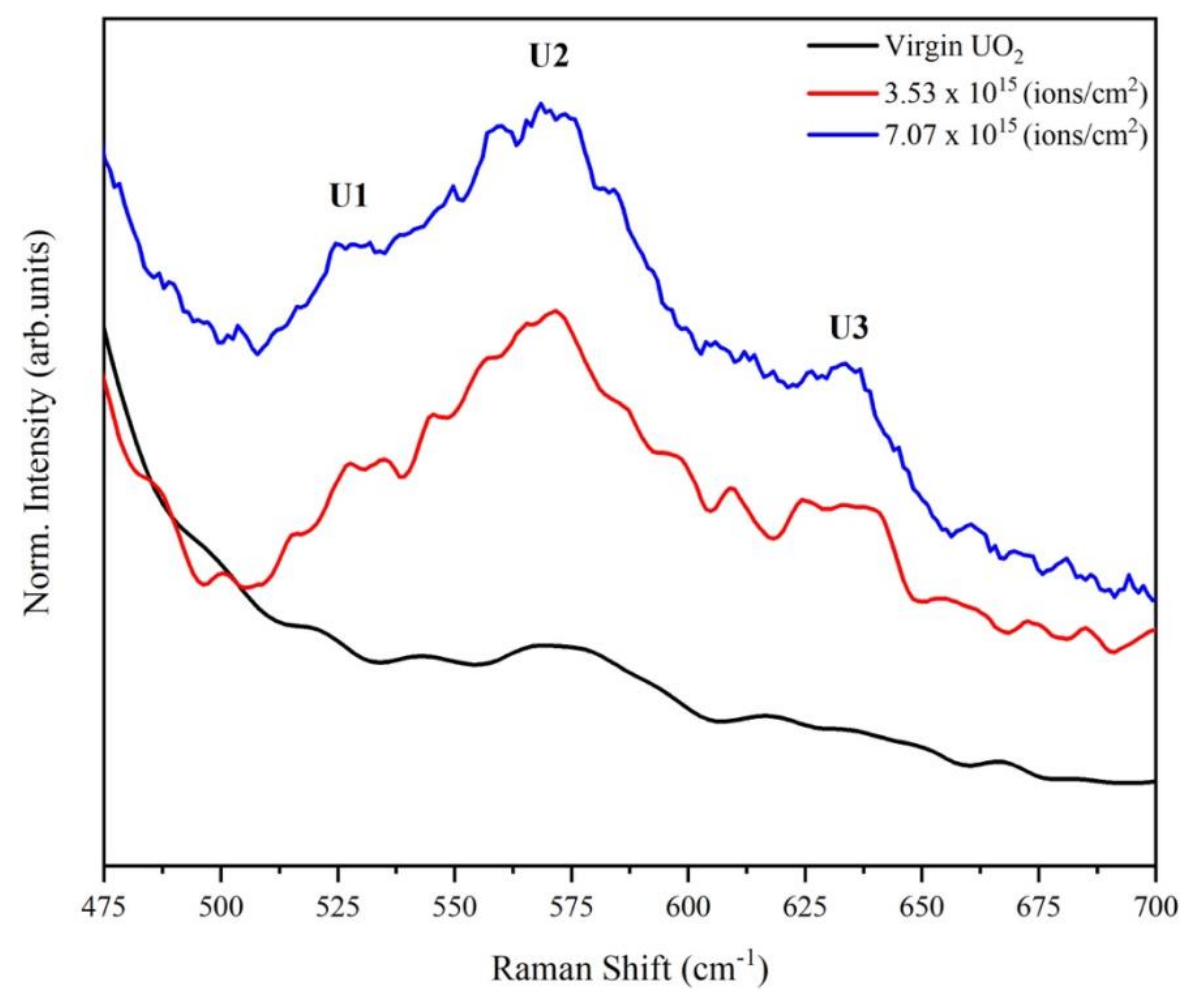

Figure 7: In situ evolution of the Raman triplet defect peaks during irradiation of the $\mathrm{UO}_{2} / \mathrm{Ar}$ system

The kinetics of the defect bands were extracted using a similar data treatment as employed for the $\mathrm{UO}_{2} / \mathrm{H}_{2} \mathrm{O}$ system and are presented in Figure 8. 


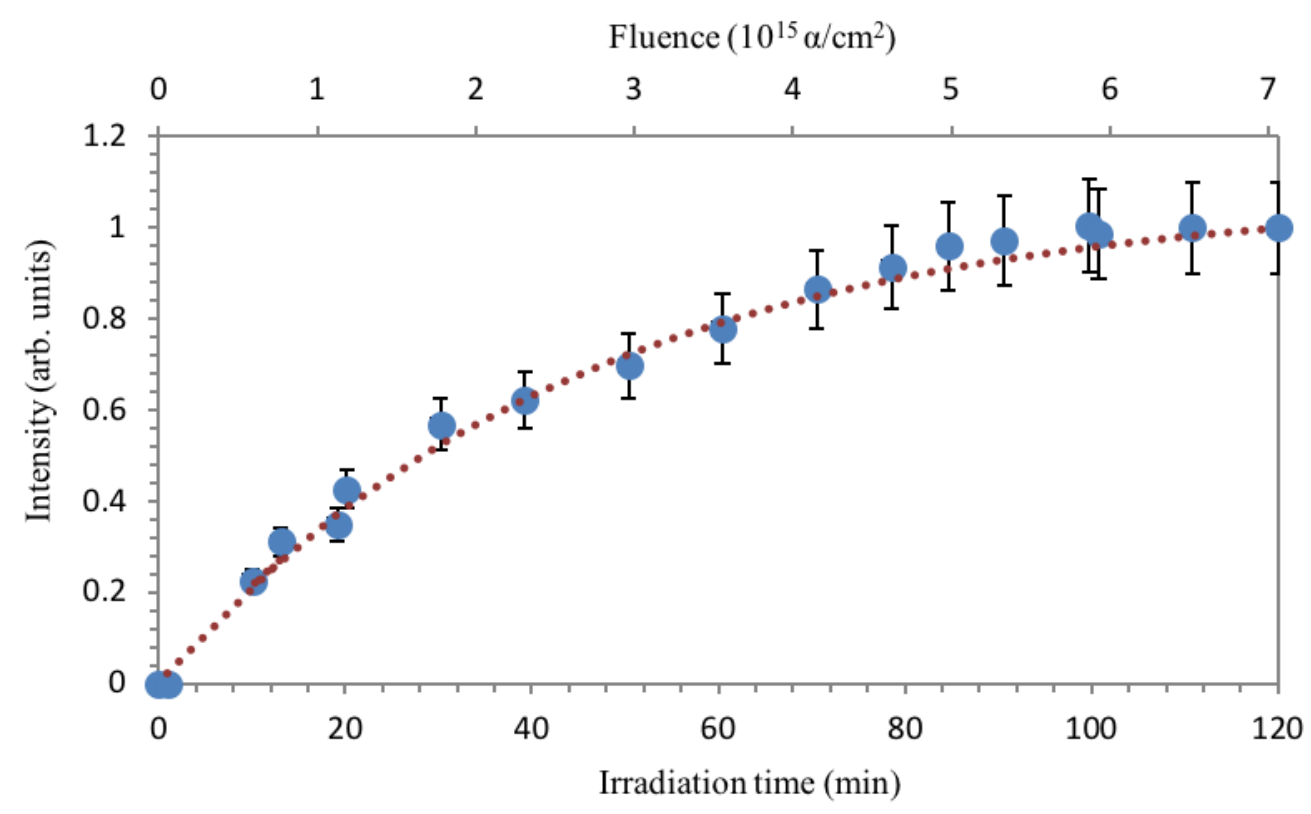

Figure 8: Kinetics of Raman defect bands intensity (Blue dots) fitted with the Direct Impact model (Red dotted line) for the $\mathrm{UO}_{2} / \mathrm{Ar}$ system under alpha irradiation. (For interpretations of the references to color in this figure, the reader is referred to the online version of this manuscript).

The kinetics of the Raman triplet defect bands for both $\mathrm{UO}_{2} / \mathrm{H}_{2} \mathrm{O}$ and $\mathrm{UO}_{2} / \mathrm{Ar}$ systems follow a unique kinetic; characterized by a rapid intensity increase during the initial stages of irradiation before reaching saturation. The initial increase of the defect bands intensity corresponds to the production of irradiation defects while the saturation phase indicates the elimination/annihilation step of the defects respectively. Guimbretière et al. [33] demonstrated that the two-staged kinetics can be fitted by a simple Direct Impact (DI) model which relates the defect concentration $(\rho D)$ and the alpha dose $(\mathrm{D} \alpha)$ (Equation 3).

$$
\mathrm{d} \rho_{D} / d D_{\alpha}=R_{\alpha}-B \rho_{D}
$$

$R_{\alpha}$ is the number of irradiation defects (I.D) produced per unit of path length traveled by alpha particles (I.D/cm. $\alpha$ ). ( $\left.\mathrm{B} \times \rho_{\mathrm{D}}\right)$ corresponds to the annihilation term describing the recombination of irradiation defects. The B-parameter defines the annealing rate constant $\left(\mathrm{cm}^{2} / \alpha\right)$ and $\rho_{\mathrm{D}}$ is in I.D $/ \mathrm{cm}^{3}$. Equation 3 can also be expressed in the form of Equation 4.

$$
\rho_{D}=\rho_{D(\infty)} x\left(1-e^{-B D_{\alpha}}\right)
$$

$\rho_{\mathrm{D}}(\infty)$ is the defect concentration at saturation.

The theoretical exponential fits of the defect bands kinetics shown in Figure $5 \&$ Figure 8 were important to set the numerical interpretations for $\rho_{\mathrm{D}(\infty)}$ and the B-parameter. The obtained values are presented in Table 2. 
Table 2: Comparison of the defect concentrations at saturation $\left(\rho_{\mathrm{D}(\infty)}\right)$ and the defect annealing parameter (B) for the $\mathrm{UO}_{2} / \mathrm{Ar}$ and $\mathrm{UO}_{2} / \mathrm{H}_{2} \mathrm{O}$ systems

\begin{tabular}{c|c|c}
\hline Scenario studied & $\boldsymbol{\rho D}(\infty)$ & Annealing Parameter (B) \\
\hline $\mathrm{UO}_{2} / \mathrm{Ar}$ & $1.10 \pm 0.023$ & $3.75 \times 10^{-16} \pm 1.93 \times 10^{-17}$ \\
\hline $\mathrm{UO}_{2} / \mathrm{H}_{2} \mathrm{O}$ & $1.02 \pm 0.022$ & $7.95 \times 10^{-16} \pm 7.29 \times 10^{-17}$ \\
\hline
\end{tabular}

Table 2 shows that the defect kinetics for the $\mathrm{UO}_{2} / \mathrm{Ar}$ can be modeled with an annealing rate constant of $3.75 \times 10^{-16} \pm 1.93 \times 10^{-17} \mathrm{~cm}^{2} / \alpha$. This observation is in good agreement with the values reported by Guimbretière et al. [33] $\left(10^{-16} \pm 10^{-17} \mathrm{~cm}^{2} / \alpha\right)$ and Weber [50] $\left(0.85 \times 10^{-16} \mathrm{~cm}^{2} / \alpha\right)$. The slight variance can be attributed to different $\mathrm{UO}_{2}$ samples density used in the mentioned studies. The fit for the $\mathrm{UO}_{2} / \mathrm{H}_{2} \mathrm{O}$ gives a B-parameter of $7.95 \times 10^{-16} \pm 7.29 \times 10^{-17} \mathrm{~cm}^{2}$, i.e., twice the value obtained for the reference $\mathrm{UO}_{2} / \mathrm{Ar}$. These findings suggest that the elimination of defects is accelerated when the irradiation experiment is carried out under a chemically reactive environment. This can be observed from Figure 9 which shows that the saturation stage for the $\mathrm{UO}_{2} / \mathrm{H}_{2} \mathrm{O}$ is attained much faster compared to the inert argon environment.

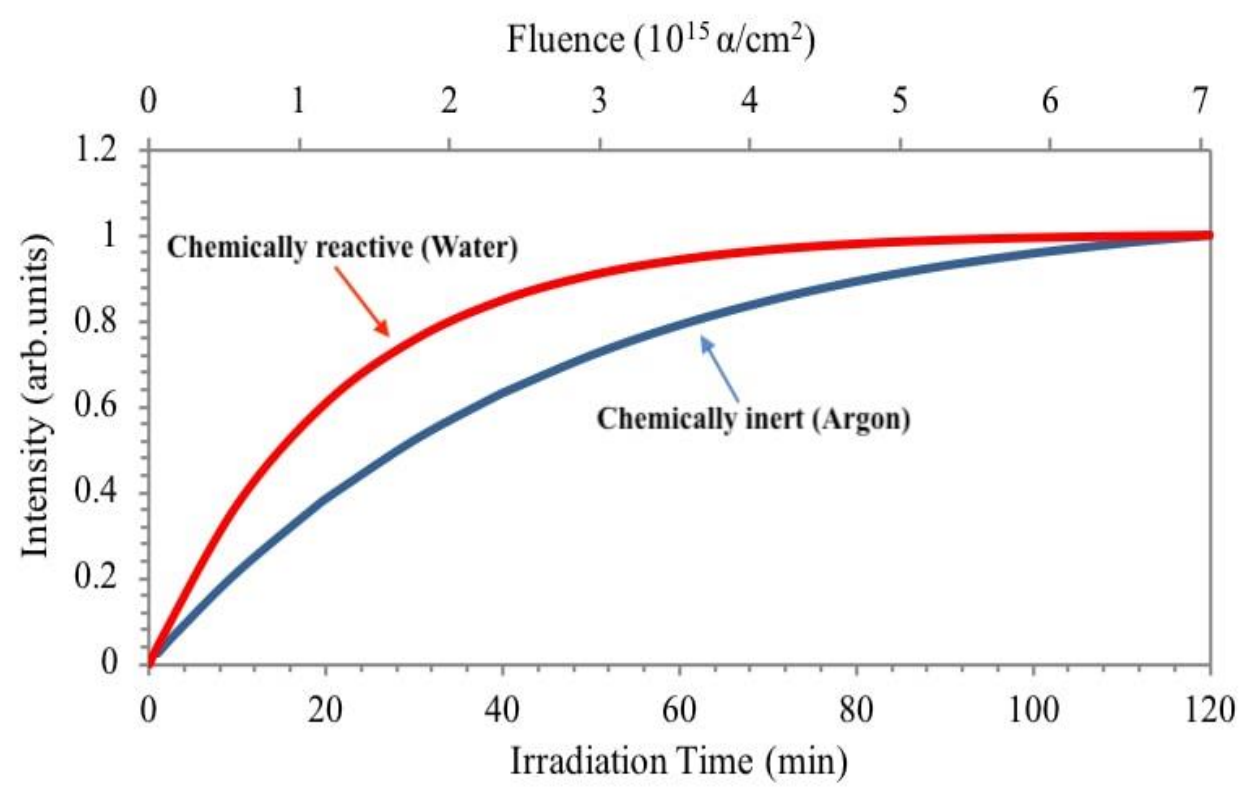

Figure 9: Comparison of the in situ irradiation defects kinetics of the $\mathrm{UO}_{2} / \mathrm{Ar}$ (Blue color) and the $\mathrm{UO}_{2} / \mathrm{H}_{2} \mathrm{O}$ (Red color). (For interpretations of the references to color in this figure, the reader is referred to the online version of this manuscript).

The difference in the kinetics can be interpreted by considering the $\mathrm{UO}_{2}$ boundary surface exposed to the contact medium during the alpha irradiation. For the $\mathrm{UO}_{2}$ leaching experiment, chemical reactions are more likely to be involved near the $\mathrm{UO}_{2}-\mathrm{H}_{2} \mathrm{O}$ interface and contribute to the dissolution of the $\mathrm{UO}_{2}$ disk. However, the increase in the defect annealing step observed during the leaching study gives indication to suggest that the alpha-induced irradiation defects may also be involved in these chemical reactions. In doing so, the $\mathrm{UO}_{2}$ boundary layer acts as sinks and governs 
the annealing of defects. Tocino et al. [51] and Corkhill et al. [19] recently highlighted the importance of atomistic defects during the dissolution of uranium mixed oxides and cerium compounds respectively. The authors showed that the high leaching rate was related to the reduced chemical durability of the materials due to the presence of crystal defects such as oxygen vacancies. These findings thus indicate that irradiation defects should also be considered in the chemical reactions occurring near the fuel matrix-water interface.

However, such chemical reactions do not hold much significance for the $\mathrm{UO}_{2} / \mathrm{Ar}$ system due to the inert chemical characteristic of the argon gas. The elimination of irradiation defects solely depends on a simple vacancy-interstitial recombination mechanism. The defects annealing step is likely to be delayed as a sufficiently high defect concentration should first be reached in the $\mathrm{UO}_{2}$ bulk.

It is worth noting that the in situ Raman analysis gives an overview regarding the behavior of irradiation damages under different interfaces but unfortunately does not allow us to identify the types of defects involved, i.e., uranium/oxygen at interstitial/vacancy positions. To complete this study, further investigations are still required to provide additional information relevant to the Raman triplet defect bands.

\section{Conclusions}

In this study, a newly designed in situ Raman installation was employed to characterize the

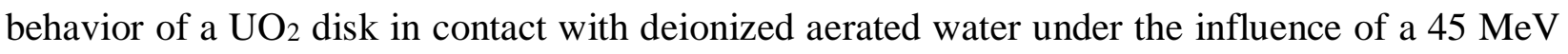
alpha beam. The objective of this work was to measure the formation kinetics of irradiation defects and the obtained data were then compared to a reference $\mathrm{UO}_{2} / \mathrm{Ar}$ system.

The irradiation defects for both $\mathrm{UO}_{2} / \mathrm{H}_{2} \mathrm{O}$ and $\mathrm{UO}_{2} / \mathrm{Ar}$ scenarios followed a unique kinetic and were fitted using a simple Direct Impact model, but the kinetics were seen to depend on experimental conditions. During the $\mathrm{UO}_{2}$ leaching study, the acquired data showed that irradiation defects are likely to be involved in chemical reactions occurring near the $\mathrm{UO}_{2}-\mathrm{H}_{2} \mathrm{O}$ interface. The $\mathrm{UO}_{2}$ boundary acts as sinks and accelerate the annealing of defects. In regard to the $\mathrm{UO}_{2} / \mathrm{Ar}$ system, it was reported that the elimination of defects solely depends on a simple interstitial-vacancy recombination mechanism. The latter was attributed to the chemically inert $\mathrm{UO}_{2}-\mathrm{Ar}$ interface.

Finally, the irradiated water solution was analyzed to study the $\mathrm{UO}_{2}$ oxidative dissolution mechanisms. It was observed that the concentration of radiolytic $\mathrm{H}_{2} \mathrm{O}_{2}$ and dissolved uranium were sufficient to allow the precipitation of secondary $\mathrm{U}(\mathrm{VI})$ phases in the form of studtite. In addition, the dissolution occurred without the formation of a $\mathrm{UO}_{2}$ oxidized layer due to the combined effects of complexing fluoride ions and slightly acidic irradiated solution. 


\section{Acknowledgments}

This work was conducted and funded within the framework of the French Tripartite Institute CEA/EDF/Framatome [Project Transport et Entreposage]. The authors are grateful to the EMIR committee and the technical staff of the CEMHTI facility. The authors also thank C. Tanguy and D. Drouan (CEA/DEN/LLCC) for their assistance with samples preparations and subsequent SEM analysis. Finally, J. Raynal and H. Rouquette (CEA/DEN/LCU) are warmly acknowledged for their contribution during XRD measurements.

\section{Data availability}

The raw/processed data that support the findings of this study are available from the corresponding author, [R. Mohun], upon reasonable request.

\section{References}

[1] D. Shoesmith and S. Sunder, J. Nucl. Mater. 190 (1992) 20-35. https://doi.org/10.1016/0022-3115(92)90072-S

[2] C. Corbel, G. Sattonnay, S. Guilbert, F. Garrido, M. Barthe and C. Jégou, J. Nucl. Mater. 348 (2006) 1-17. https://doi.org/10.1016/j.jnucmat.2005.05.009

[3] A. Poulesquen and C. Jégou, Nucl. Tech. 160 (2007) 337-345. https://doi.org/10.13182/NT07-A3904

[4] G. Sattonnay, C. Ardois, C. Corbel, J. Lucchini, M. Barthe, F. Garrido and D. Gosset, J. Nucl. Mater. 288 (2001) 11-19. https://doi.org/10.1016/S0022-3115(00)00714-5

[5] C. Jégou, B. Muzeau, V. Broudic, A. Poulesquen, D. Roudil, F. Jorion and C. Corbel, Radiochim. Acta. 93 (2009) 35-42. https://doi.org/10.1524/ract.93.1.35.58294

[6] G. Thomas and G. Till, Nucl. Chem. Waste Management. 5 (1984) 141-147. https://doi.org/10.1016/0191-815X(84)90044-5

[7] L. Johnsson, D. Shoesmith, G. Lunansky, M. Bailey and P. Termaine, Nucl. Tech. 56 (1982) 238-253. https://doi.org/10.13182/NT82-A32851

[8] M. Magnin, C. Jégou, R. Caraballo, V. Broudic, M. Tribet, S. Peuget and Z. Talip, J. Nucl. Mater. 462 (2015) 230-241. https://doi.org/10.1016/j.jnucmat.2015.03.029

[9] R. Forsyth and L. Werme, J. Nucl. Mater. 190 (1992) 3-19. https://doi.org/10.1016/0022-3115(92)90071-R 
[10] V. Gromov, Radiat. Phys. Chem. 18 (1981) 135-146.

https://doi.org/10.1016/0146-5724(81)90071-6

[11] F. Clarens, J. De Pablo, I. Diez-Pérez, I. Casas, J. Giménez and M. Rovira, Environ. Sci. Technol. 38 (2004) 6656-6661. https://doi.org/10.1021/es0492891

[12] S. Sunder, D. Shoesmith, H. Christensen, N. Miller and M. Bailey, Mater. Res. Soc. Symp. Proc. 176 (1989) 457. https://doi.org/10.1557/PROC-176-457

[13] S. Sunder, D. Shoesmith, H. Christensen and N. Miller, J. Nucl. Mater. 190 (1992) 78-86. https://doi.org/10.1016/0022-3115(92)90078-Y

[14] C. Jégou, B. Muzeau, V. Broudic, S. Peuget, A. Poulesquen, D. Roudil and C. Corbel, J. Nucl. Mater. 341 (2005) 62-82. https://doi.org/10.1016/j.jnucmat.2005.01.008

[15] P. Finn, J. Hoh, S. Wolf, S. Slater and J. Bates, Radiochim. Acta. 74 (1996) 65-71. https://doi.org/10.1524/ract.1996.74.special-issue.65

[16] J. Cobos, T. Wiss, T. Gouder and V. Rondinella, Mater. Res. Soc. Symp. Proc. 757 (2002) II9.2. https://doi.org/10.1557/PROC-757-II9.2

[17] W. Weber, R. Ewing, C. Catlow, T. Diaz de la Rubia, L. Hobbs, C. Kinoshita, H. Matzke, A. Motta, M. Nastasi, E. Salje, E. Vance and S. Zinkle, J. Mater. Res. 13 (1998) 14341484. https://doi.org/10.1557/JMR.1998.0205

[18] W. Weber and F. Roberts, Nucl. Tech. 60 (1983) 178-198. https://doi.org/10.13182/NT83-A33073

[19] C. Corkhill, D. Bailey, F. Tocino, M. Stennett, J. Miller, J. Provis, K. Travis and N. Hyatt, ACS Appl. Mater. Interfaces. 8 (2016) 10562-10571. https://doi.org/10.1021/acsami.5b11323

[20] D. Horlait, N. Clavier, S. Szenknect, N. Dacheux and V. Dubois, Inorg. Chem. 51 (2012) 3868-3878. https://doi.org/10.1021/ic300071c

[21] A. Popel, S. Le Solliec, G. Lampronti, J. Day, P. Petrov and I. Farnan, J. Nucl. Mater. 484 (2017) 332-338. https://doi.org/10.1016/j.jnucmat.2016.10.046

[22] K. Ollila, Mater. Res. Soc. Symp. Proc. 127 (1988) 337. https://doi.org/10.1557/PROC-127-337

[23] H. Matzke, J. Nucl. Mater. 190 (1992) 101-106. https://doi.org/10.1016/0022-3115(92)90080-5 
[24] M. Amme, B. Renker, B. Schmid, M. Feth, H. Bertagnolli and W. Dobelin, J. Nucl. Mater. 306 (2002) 202-212. https://doi.org/10.1016/S0022-3115(02)01291-6

[25] C. Jégou, R. Caraballo, S. Peuget, D. Roudil, L. Desgranges and M. Magnin, J. Nucl. Mater. 405 (2010) 235-243. https://doi.org/10.1016/j.jnucmat.2010.08.005

[26] G. Guimbretière, L. Desgranges, A. Canizarès, G. Carlot, R. Caraballo, C. Jégou, F. Duval, N. Raimboux, M. Ammar and P. Simon, Appl. Phys. Lett. 100 (2012) 251914. https://doi.org/10.1063/1.4729588

[27] M. Naji, J. Colle, O. Beneš, M. Sierig, J. Rautio, P. Lajarge and D. Manara, J. Raman Spectrosc. 46 (2015) 750-756. https://doi.org/10.1002/jrs.4716

[28] C. Jégou, M. Gennisson, S. Peuget, L. Desgranges, G. Guimbretière, M. Magnin, Z. Talip and P. Simon, J. Nucl. Mater. 458 (2015) 343-349. https://doi.org/10.1016/j.jnucmat.2014.12.072

[29] Ziegler J.F., SRIM Software 2011. Available online: http://www.srim.org

[30] A. Canizarès, G. Guimbretière, Y. Tobon, N. Raimboux, R. Omnée, M. Perdicakis, B. Muzeau, E. Leoni, M. Alam, E. Mendes, D. Simon, G. Matzen, C. Corbel, M. Barthe and P. Simon, J. Raman Spectrosc. 43 (2012) 1492-1497. https://doi.org/10.1002/jrs.4088

[31] S. Le Caër, Water. 3 (2011) 235-253. https://doi.org/10.3390/w3010235

[32] J. Spinks and R. Woods, An Introduction to Radiation Chemistry, 3rd ed., New York, USA: Wiley-Interscience publication, 1991. https://doi.org/10.1002/bbpc.19910950346

[33] G. Guimbretière, L. Desgranges, A. Canizarès, R. Caraballo, F. Duval, N. Raimboux, R. Omnée, M. Ammar, C. Jégou and P. Simon, Appl. Phys. Lett.103 (2013) 041904. https://doi.org/10.1063/1.4816285

[34] G. Hochanadel, J. Phys. Chem. 56 (1952) 587-594. https://doi.org/10.1021/j150497a008

[35] G. Guimbretière, A. Canizarès, N. Raimboux, J. Joseph, P. Desgardin, L. Desgranges, C. Jégou and P. Simon, J. Raman Spectrosc. 46 (2015) 418-420. https://doi.org/10.1002/jrs.4661

[36] L. Desgranges, G. Guimbretière, P. Simon, F. Duval, A. Canizarès, R. Omnée, C. Jégou and R. Caraballo, Nucl. Instrum. Methods B. 327 (2014) 74-77. https://doi.org/10.1016/j.nimb.2013.10.083

[37] T. Livneh and E. Sterer, Phys. Rev. B. 73 (2006) 085118. https://doi.org/10.1103/PhysRevB.73.085118 
[38] Z. Talip, T. Wiss, P. Raison, J. Paillier, D. Manara, J. Somers and R. Konings, J. Am. Ceram. Soc. 98 (2015) 2278-2285. https://doi.org/10.1111/jace.13559

[39] R. Mohun, L. Desgranges, J. Léchelle, G. Guimbretière, P. Simon, A. Canizarès, F. Duval, C. Jégou, M. Magnin, N. Dacheux, N. Clavier, C. Valot and R. Vauchy, Nucl. Instrum. Methods B. 374 (2016) 67-70. https://doi.org/10.1016/j.nimb.2015.08.003

[40] A. Traboulsi, J. Vandenborre, G. Blain, B. Humbert, F. Haddad and M. Fattahi, J. Nucl. Mat. 467 (2015) 832-839. https://doi.org/10.1016/j.jnucmat.2015.10.061

[41] K. Walenta, American Mineralogist. 59 (1974) 166-171.

[42] D. Shoesmith and S. Sunder, 1991. [Online]. http://www.iaea.org/inis/collection/NCLCollectionStore/_Public/23/078/23078146.pdf [Accessed 25 July 2017].

[43] H. Kubatko, K. Helean, A. Navrotsky and P. Burns, Science. 302 (2003) 1191-1193. https://doi.org/10.1126/science.1090259

[44] M. Torrero, E. Baraj, J. De Pablo, J. Giménez and I. Casas, Int. J. Chem. Kinet. 29 (1997) 261-267. https://doi.org/10.1002/(SICI)1097-4601(1997)29:4<261::AID-KIN4>3.0.CO;2-S

[45] D. Manara and B. Renker, J. Nucl. Mater. 321 (2003) 233-237. https://doi.org/10.1016/S0022-3115(03)00248-4

[46] H. He and D. Shoesmith, Phys. Chem. Chem. Phys. 12 (2010) 8109-8118. https://doi.org/10.1039/B925495A

[47] L. Desgranges, G. Baldinozzi, P. Simon, G. Guimbretière and A. Canizarès, J. Raman Spectrosc. 43 (2012) 455-458. https://doi.org/10.1002/jrs.3054

[48] J. Elorrieta, L. Bonales, N. Rodriguez-Villagra, V. Baonza and J. Cobos, Phys. Chem. Chem. Phys. 18 (2016) 28209-28216. https://doi.org/10.1039/C6CP03800J

[49] R. Böhler, A. Quaini, L. Capriotti, P. Cakir, O. Benes, K. Boboridis, A. Guiot, L. Luzzi, R. Konings and D. Manara, J. Alloys Comp. 616 (2014) 5-13. https://doi.org/10.1016/j.jallcom.2014.07.055

[50] W. Weber, J. Nucl. Mater. 98 (1981) 206-215. https://doi.org/10.1016/0022-3115(81)90400-1

[51] F. Tocino, S. Szenknect, A. Mesbah, N. Clavier and N. Dacheux, Prog. Nucl. Energy. 72 (2014) 101-106. https://doi.org/10.1016/j.pnucene.2013.09.014 